\title{
Garrett: de fingimentos e conclusões (Formas que teve o escritor de fazer o seu próprio elogio)
}

Maria Fernanda de Abreu* 
“[...] los prólogos no son proyectos, por muy preliminares que parezcan, sino simulacros de conclusiones, [...]."

(Claudio Guillén, Múltiples Moradas, 1998)

“Declaram-se típicas, simbólicas e míticas estas viagens. Faz o A. modestamente o seu próprio elogio."

(Do sumário do capítulo II das Viagens na Minha Terra)

Fui sempre muito pouco amigo de dar satisfações. Porém esta minha repugnância não é filha de presunção, nem de orgulho. De todo o meu coração o digo, e todos os que me conhecem, o sabem. Nasce da persuasão, em que estou, de que a justificação duma coisa está na maneira por que essa coisa se faz. E aplicando esta generalidade às composições literárias, cada vez me convenço mais que os prólogos, prefácios, avisos a leitores, etc., nada fazem, nem fizeram, nem farão nunca ao conceito, que da obra se forma.

Estas palavras escreveu-as o jovem J .B. da Silva Leitão D'Almeida G arrett na "Advertência" que apôs ao volume no qual, em 1821, editou por primeira vez o seu poema $O$ retrato de Vénus seguido de um Ensai o sobre a história da pintura. ${ }^{1}$ 
Desde já registo que, na edição das Obras de AImei da Garrett, da Lello, 1963, esta "advertência" aparece como texto introdutório ao Bosquejo da história da poesi a elíngua portuguesa o que, obviamente, não faz sentido, já que nele G arrett se refere a un poema e a un ensaio; o erro foi repetido pela edição do Circulo de Leitores, 1984.

Dizia, pois, o jovem G arrett que era "muito pouco amigo de dar satisfações". Todavia, por razões que aduz no seguimento do texto, acaba por "resolv[er-se] a dar satisfação". Ainda bem que o faz. E ainda bem que muitas outras vezes, ao longo da sua carreira de escritor, de cidadão, e de activo militante da vida política e cultural, acabou por resolver-se "a dar satisfação": aos leitores, aos compatriotas, a amigos e inimigos. E fê-lo nos tais "prólogos, prefácios, avisos a leitores, etc.".

Afinal, parece ter sido ele próprio (deste "parece" se falará mais adiante) quem, em terceira pessoa, numa sua Biografia chamou a atenção para prefácios seus e os elogiou, ao dizer que o 3 o volume das suas obras era "volume precioso, que contém o Auto de Gil Vicente, a Mérope, e dois originalíssimos prefácios, que servem de introdução àquelas peças dramáticas, e que estão escritos com uma graça e vivacidade de estilo inteiramente novas em a nossa língua." Também, no mesmo lugar, elogia a M emória com que apresentou o Frei Luis de Sousa ao Conservatório R eal considerando-a "um verdadeiro prólogo de Victor H ugo, uma nova obra gerada ao pé da outra."

Muitos, variados, e de variada natureza foram, pois, os textos em que G arrett nos "deu satisfação" da sua obra e das circunstâncias dela: desde a defesa a que o forçaram instaurando-Ihe um processo pelo seu O retrato de Vénus (1822) até aos textos introdutórios de $\mathrm{O}$ arco de Sant'Ana (1844, 1850, 1851) ${ }^{2}$, também estes de defesa, ao longo de cerca de trinta anos, foi-nos ele deixando, ao mesmo tempo que informações de carácter editorial, um precioso acervo de teorias e doutrinas estéticas e de história literária (em particular no campo da poesia e do teatro) assim como, em variados casos, férteis directrizes para a leitura, interpretação e análise de cada obra em concreto. Todos recordamos, como peça fundamental deste corpus, a já referida "M emória ao Conservatório" que, a 6 de Maio de 1843, Ihe serviu para apresentar o Frei Luís de Sousa, tão importante para a definição programática da renovação do teatro português como o já tinham sido os anteriores prefácios a outras obras teatrais, entre elas o prefácio da primeira edição do Catão. E não esquecemos tão pouco, o prefácio da primeira edição do Camões (1825), publicado anonimamente, em que nos revela que é bem consciente nele a intenção de com o poema introduzir o movimento literário romântico, nem a "no-

2 Dou como datas dos textos de natureza prefacial as que se encontram no pé dos mesmos. 
ticia do autor" da Lírica de J oão Míni mo (1828) como juízo à poesia arcádica e contextualização do aparecimento da nova poesia ou, do mesmo ano, a carta ao seu amigo Duarte Lessa com que prefaciou a Adozinda, complementada, mais tarde, para o conhecimento de uma rica tradição peninsular e do papel da sua recuperação no aprofundamento do romantismo, com a "introdução" ao Romanceiro (1843). ${ }^{3}$

Não menos importante é, em minha opinião, essa outra declaração que, quase no final da vida (1853), faz numa breve apresentação das Fábulas e contos confirmando que a sua carreira se tinha diversificado e multiplicado em "desvairados assuntos e géneros", revelando, além disso que o tinha feito não "por vaidade" mas por "honrar" a língua portuguesa que ele sempre tinha sentido "[ser] para todo o género de composições", assim, ao mesmo tempo, revelando o objectivo experimental que, além de outros, teriam guiado a sua carreira de escritor.

\section{De fingimentos...}

Deu, pois, Garrett, longa e variada satisfação da sua obra. E, repito, ainda bem que o fêz. Nem sempre, porém, diz-se, o fêz nesta primeira pessoa que aqui Ihe ouvimos. Mais de uma vez Garrett terá posto na voz de uma terceira pessoa, não identificada, ou de um plural, "os editores", textos de auto-apresentação que, imediatamente, foram lidos como sendo da sua autoria ou, mais tarde, numa ou noutra circunstância, atribuídos a ele próprio.

É este o corpo garrettiano que agora quero recordar e analisar, sendo consciente de que trabalho sobre uma hipótese e não uma certeza - a hipótese de que se tratam, efectivamente de textos escritos pelo próprio G arrett - uma certeza, a da autoria, a que, por outro lado, só nos poderiamos aproximar se sobre esses textos se posassem os olhos da crítica textual que até hoje pouco tem feito pela fixação da sua obra, nem sequer da mais divulgada.

Talvez valha a pena confessar - para que o risco seja ainda maior ou para abonar o campo dos possíveis detractores - que de uma forma que não é, pois, científica, creio, sem grandes dúvidas, que esses textos são da autoria do escritor e que se o não forem, obviamente, grande parte da minha análise cairá por terra, e pela base. A começar pela ideia de "fingimento" que muito me interessa na encenação desses textos e que deixo expressa no título deste comentário. Uma encenação que Ihe permitiu ao "autor do texto" - já agora recorro eu à mesma estraté-

Agostinho da Silva reuniu em volume - Almeida Garrett, Doutrinas de Estéti ca Literária. Prefácio e notas de Agostinho da Silva. Lisboa, Textos Literários, 1938 - alguns destes textos assim como passagens de obras que o autor da antologia considerou ajustar-se ao objectivo da mesma anunciado no título. 
gia ambígua - não só proporcionar miudas informações sobre a obra de Garrett mas também, e sobretudo, algo que os textos assinados pelo próprio escritor lhe não permitiam fazer com o mesmo á-vontade: o elogio rasgado das suas extraordinárias qualidades de escritor e de cidadão.

As Viagens na Minha Terra são um daqueles livros raros que só podiam ser escritos por quem, como o autor de Camões e de Catão, de D. Branca e do Portugal na Balança da Europa, do Auto de Gil Vicente e do Tratado de Educação, do Alfageme e de Fr. Luis de Sousa, do Arco de Sant'Ana e da História Literária de Portugal, de Adozinda e das Leituras Históricas e de tantas produções de tão variado género, possui todos os estilos e, dominando uma língua de imenso poder, a costumou a servir-Ihe e obedecer-Ihe; - por quem com a mesma facilidade sobe a orar na tribuna, entra no gabinete nas graves discussões e demonstrações da ciência - voa às mais altas regiões da lírica, da epopeia e da tragédia, lida com as fortes paixões do drama, e baixa às não menos difíceis trivialidades da comédia; por quem ao mesmo tempo, e como que mudando de natureza, pode dar-se todo às mais áridas e materiais ponderações da administração e da política, e redigir com admirável precisão, com uma exacção ideológica que talvez ninguém mais tenha entre nós, uma lei administrativa ou de instrução pública, uma constituição política, ou um tratado de comércio. ${ }^{4}$

Este estrondoso elogio de Garrett - que longa e, todavia, tão incompletamente transcrevo - pode ler-se no prólogo à primeira edição em volume das Viagens na Minha Terra, de $1846^{5}$. Normalmente transcrito como “Prólogo dos editores" e escrito, como se vê, em terceira pessoa, rapidamente, no seu tempo, correu a ideia de que o seu autor era o próprio Almeida Garrett que, assim, despudoradamente, esmiuçava os variados e imensos atributos que faziam dele a mais importante figura pública da sua época, no campo das letras e também não pouco no da política.

Gomes de Amorim, o seu dedicado biógrafo e confessado discípulo, sai à liça dos comentários que lhe tildam o mestre de vaidoso mas não nos tira as dúvidas quanto à verdadeira autoria do inesquecível elogio:

De quantos elogios acusam o autor de ter tecido a si próprio, e posto às costas dos seus editores, se o prólogo da segunda edição ${ }^{6}$ das viagens foi escrito por ele, nenhum revela maior vaidade, segundo o juízo dos contemporâneos; em meu humilde conceito, porém,

4 Cito da que deve ser considerada a melhor edição das Viagens nos nossos dias: Introdução e notas de Augusto da Costa Dias. Lisboa, Portugália E ditora, 1963.

5 A parece também reproduzido como “P rólogo da segunda edição" .Assim o designa, por exemplo, G omes de Amorim, que considera como primeira a sua publicação na Revista Universal Lisbonense. Lamentavelmente, a maioria das edições das Viagens, disponíveis no mercado, não chegam sequer a reproduzi-lo.

6 Ver nota anterior. 
está ali a mais cabal pintura que de tamanho engenho se podia obter em tão pequena tela. Tudo que diz de si é de uma verdade tão indiscutível, que só há a lastimar o não ter sido de outra pena aquele elogio merecidíssimo, se com efeito o produziu a sua. ${ }^{7}$

Gomes de Amorim não nos tira aqui as dúvidas sobre a autoria do prólogo. Mas parece inclinado a admitir que assim seja na lástima que manifesta e talvez ainda mais no juízo que emite sobre a "verdade" do que ali se diz. Pessoalmente, confesso que nem sequer chego ao ponto de lastimar que o elogio tenha saído da pena do próprio Garrett. Dou graças aos deuses pelo facto de não me sentir obrigada a defender-Ihe a honra perante os detractores, e à distância de século e meio lembro que o escritor não fazia mais - nem menos - do que o seu mestre e modelo Camões tinha já feito quase três séculos antes: ter a consciência do seu imenso valor de escritores e a coragem de afirmá-lo, alto e bom som, preto no branco, na praça pública das invejas ou das indiferenças (Outros, depois, como Fernando Pessoa e J orge de Sena hão-de seguir-Ihes o gesto e não com menos verdade e pertinência).

Fica-nos, pois, não a lástima mas, pelo contrário, o agradecimento de um texto que, como diz G omes de A morim e com ele assentimos plenamente, nos dá, para sempre, uma "cabal pintura" do engenho garrettiano.

$M$ ais adiante, voltarei à forma como esta "cabal pintura" sintetiza, de forma exemplar, o percurso do escritor e a sua prática literária dando-nos, ao mesmo tempo, pistas valiosíssimas para a leitura da obra. Quero, todavia, antes recordar como, afinal, apenas dois anos antes deste prólogo, tinham os seus contemporâneos visto aparecer nas páginas do Universo pittoresco, na secção "Biographia", um outro texto onde, em cerca de doze longas páginas, distribuidas em três entregas, se apresentava ao leitor "O conselheiro J .B. de Almeida Garrett". ${ }^{8}$ Nele, também em terceira pessoa, se traçava um retrato da vida e da obra do escritor, não menos elogioso que o "P rólogo" das Viagens. E aqui parece não se pôr sequer dúvidas quanto à autoria garrettiana do mesmo.

O próprio G omes de Amorim, logo no início da sua biografia de Garrett, indica que está a utilizar o "manuscrito original" daquele texto e identifica o seu autor, com as seguintes palavras que são, ao mesmo tempo, e tal como o juizo que há-de pronunciar sobre o "prólogo" das Viagens, de pena por esta "fragilidade": “I nfelizmente, porém, até nos maiores engenhos se revela a fragilidade humana; e não foi este [Garrett] isento dela. Nas sua biografia, publicada no Universo pittoresco, da qual possuo o manuscrito original, escreveu ele, falando de si: - 'aque-

F. GOMES DE AM ORIM, Garrett - Memórias Biográficas. Tomo III. Lisboa, Imprensa Nacional, 1884: 75. Universo Pittoresco, Tomo III, 1843- 1844. 
las maneiras polidas, que só dá o nascimento e alta educação...'"9. Depois, ao longo dos três tomos das suas Memórias biográficas de Almeida G arrett, por aqui e por ali, há-de G omes de A morim transcrever passagens daquele texto que sempre designa de Biographia manuscrita", afirmando, uma e outra vez, a autoria garrettiana do mesmo. Por exemplo, a certa altura, reproduz uma longa passagem do texto publicado no Uni verso pittoresco onde se narra a perda, em naufrágio, do poema Magriço, se diz que ela "é uma verdadeira perda para a literatura portuguesa" e se lamenta que a memória do autor não possa reconstitui-la, terminand o com as seguintes palavras:"mas temos-Ihe ouvido protestar [ao Autor] que nunca mais poderia achar-se nas diversas disposições de ânimo em que estivera ao compor aqueles variados cantos. G rande lástima que assim seja.". G omes de A morim comenta, então: “E stá a ver-se e a sentir-se neste estilo o autor da obra perdida!"10. Além disso não se limita a reproduzir o que já fora publicado naquela conhecida revista fazendo questão de reproduzir igualmente outras passagens, não publicadas, do manuscrito que diz ter em seu poder ${ }^{11}$.

Gomes de Amorim confirma, pois, que a A Biografia é da autoria do próprio G arrett e Teófilo Braga publica-a já como “A uto-biografia”12. M as confirma mais, o primeiro, e sem parecer estranhá-lo: que G arrett, também noutros momentos, pôs em nome dos editores, ou da redacção, quando se tratava de textos aparecidos em revistas, palavras que eram suas. Assim, informa ele: “Publicou-se também em 1845 a quarta edição do Catão, na qual disse o autor, em nome dos editores, que essa tragédia lançara os fundamentos em Portugal do teatro contemporâneo". ${ }^{13}$

E é de facto verdade que, em 1845, aparece na Imprensa Nacional a quarta edição do Catão com um texto prefacial, que começa com estas palavras: "Sempre mais correcto e progressivamente melhorado por seu escrupuloso e infatigável autor, o Catão sai, nesta quarta edição autêntica, tão perfeito quanto a uma obra humana é dado sê-lo." E algo mais ali se diz que me interessa à ideia que aqui defendo de que os textos prefaciais de Garrett são peças fundamentais para uma avaliação mais correcta e matizada do entendimento da obra do escritor no seu contexto histórico-literário. Assim, aí se defende não só que o Catão “lançou os fundamentos do teatro contemporâneo" (português, deduz-se) mas também que

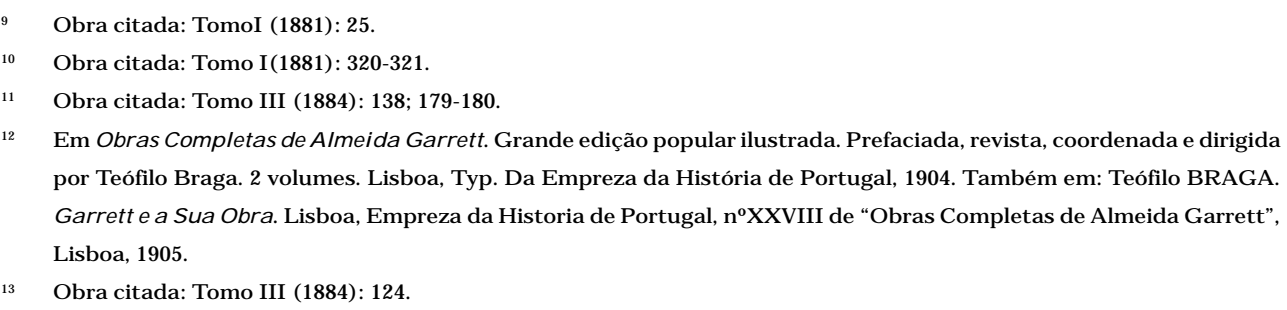
por Teófilo Braga. 2 volumes. Lisboa, Typ. Da Empreza da História de Portugal, 1904. Também em: Teófilo BRAGA. Garrett e a Sua Obra. Lisboa, Empreza da H istoria de Portugal, noXXVIII de “Obras Completas de AImeida Garrett”, Lisboa, 1905.

13 Obra citada: Tomo III (1884): 124. 
as obras teatrais do autor que se Ihe seguiram "o vão ed ificando por um estilo que nos não deixa cair nas extravagâncias e exagerações desse romantismo efémero que já vai passand o na E uropa, e que após si traz a inevitável reacção que também já em F rança se sente." E o leitor fará o favor de relacionar o que aqui se diz com outra frase célebre que, pela mesma altura, escutaremos ao autor das Viagens: "R omântico, Deus me livre de o ser - ao menos, o que na algaravia de hoje se entende por essa palavra." (cap. VIII).

É também em 1845 que G arrett publica, "sem nome de autor", o I volume do seu $O$ arco de Sant'Ana. A propósito da dedicatória, que no início do I volume faz o autor ao coronel J oão Pedro Soares de Luna, dizendo que a escreve de uma aldeia do M inho e assinando como "O Numero 72" - dedicatória que "não é menos digna de ler-se e de meditar-se", na opinião de Gomes de A morim - comenta este que G arrett "fingia não querer que se soubesse de quem era o romance, dando a entender que este vinha de tão longe."14

Mais tarde, voltarei a este Fingia não querer que se soubesse... Mas, por agora, interessa-me continuar com O arco. Gomes de Amorim dá conta dos sucessivos artigos de ataque e de defesa do livro aparecidos, então, nos jornais; destes, destaca a "introdução" a uma resposta de defesa que "parece do próprio Garrett, conquanto se publicasse em nome da redacção.". A partir de alguns de aqueles artigos reproduzidos por Gomes de Amorim, deduzimos que, afinal, o recurso à figura do "editor" de que Garrett deitou mão neste seu romance - e que noutro momento e noutro contexto, enfoquei e analisei como um recurso ficcional, inserido numa longa e persistente tradição literária, de que destaca o Dom Quixote de Cervantes ${ }^{15}$ - deu, pelo menos, azo a ironias que jogavam com a "suposta" identidade do autor.

Do próprio G arrett, segundo G omes de Amorim, e "comquanto se publicasse em nome da redacção", são estas palavras, aparecidas na Revista universal lisbonense, ${ }^{16}$ :

Diz-se que o A. do Arco de Sant'Ana tretende opor-se à reacção religiosa do século presente e fazer com que voltemos ao filosofismo do século passado. A asserção parece-nos de todo infundada.

O A. do romance bem claro e positivo se expressa sobre essa reacção religiosa e moral que ele tanto aplaude, tanto aprova, e, sem receio de muito aventurar, cremos poder dizer que bastante ajudou entre nós. O u nos erram muito bem fundadas conjecturas, ou a pessoa

Obra citada. Tomo III: 115-121.

5 Abreu, Maria Fernanda de. Cervantes no Romantismo Português. Cavalei ros andantes, manuscritos encontrados e gargalhadas moralíssimas. Lisboa, Ed.Estampa, 1994.: 207-239.

16 tomo V, 1845-46: 18. 
que supomos ser, pelo menos, editor do 'Arco de Sant'Ana' é a mesma que em outras obras bem conhecidas levantou o pendão dessa reacção, que a dirigiu, que a excitou, que fez mudar os que já estavam noutro caminho, que instigou a começar nele os que ainda não tinham começado. E se a história literária deste século em Portugal forçosamente tem de confessar (ainda que a escrevam os mais invejosos inimigos) que a reacção, que a revolução moral da nossa literatura foi capitaneada pelo A . de Camões, de Catão, de Adozi nda, do Alfageme, do Gil Vicente, de Fr. Luis de Sousa, do Tratado deEducação, do Portugal na Balança da Europa, e de tantas obras em tantos e tão diversos géneros - a crítica contemporânea também não poderá, sem injustiça, acusar o A. ou pelo menos o editor do 'Arco de Sant'Ana' de querer obstar a essa reacção.

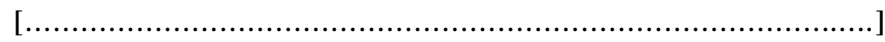

Não quer, não quer decerto - nós o juramos por ele - não que o A . do 'A rco de Sant'A na' que voltemos ao fil losofi smo que tudo derrancou. Como o há-de querer ele, ele que o denunciou, ele que o escarnece, que o acusa, que o fustiga, ele, primei ro homem liberal de Portugal que ousou fazê-lo, e conservar-se liberal, e protestar que a liberdade, que a sã filosofia, que a verdadeira ciência e a verdadeira política o renegavam e expulsavam?

Este texto é quase contemporâneo do "P rólogo" das Viagens. Por sinal (por acaso?) encontra-se, na R evista, logo a seguir ao capítulo II das Viagens que, por então, como se sabe, estava em vias de publicação na mesma. As palavras são semelhantes, basta atentar nalgumas passagens, a forma de argumentação a mesma, e é-o, sobretudo, o "fingimento": alguém, que não assina, "editores" ou "redacção", sai à liça demonstrando conhecer bem a obra do "Sr. Garrett", a sua carreira literária e cívica, o seu lugar, de pioneiro e de realizador "de tantos e tão diversos géneros", os seus princípios éticos e filosóficos e o seu papel na construção e implantação do liberalismo.

Se atentarmos nas datas destes vários textos em que uma "terceira pessoa", sem identificação precisa, vem apresentar e, se fôr caso disso, defender Garrett uma pessoa não identificada que, no entanto, mais de uma vez, ousa "jurar" em nome dele - vemos que eles se situam cronologicamente entre 1844 e 1846. São, recordemos: a Bi ografia publicada no Universo pittoresco; o prefácio da 4a edição do Catão; o texto publicado na Revista universal lisbonense a propósito de 0 arco de Sant'Ana e o prólogo dos "editores" das Viagens na minha terra.

Não é o único momento em que encontramos textos de apresentação das suas obras com características semelhantes: lembremos o prefácio da 2āedição do Catão (Londres, 1830) ou "A quem ler" que antecede a publicação de Fábulas e contos (1853). Mas a acumulação daqueles num curto período pode levar-nos a pensar que eles correspondem a uma época em que o escritor, situado politicamente na oposição, depois do seu papel nas lutas liberais, e num ponto altíssimo da sua carreira literária, sentiu a necessidade de proclamar bem alto, e sem os 
entraves da falsa modéstia, os seus méritos e o seu lugar na vida política, cultural e literária da pátria pela qual, de facto, tanto tinha feito.

Sigamos, então, mais de perto, um desses textos: cronologicamente, o primeiro do corpus que tenho vindo a invocar: a Biografia.

Começo desde já por pôr em questão uma data. Tanto Gomes de Amorim como Teófilo B raga indicam a data de 1843 para o Tomo III do Universo pittoresco onde aparece a "Biografia". No entanto, uma passagem do texto alerta para a incorrecção da mesma ao dizer: "Nos fins do ano passado (1843) [...]", o que leva a supor que, pelo menos, uma parte terá sido publicada em 1844, ainda que, por outro lado, não se registe nele nenhuma referência às Viagens na mi nha terra, já começadas a publicar na Revista universal lisbonense. De facto, trata-se do Universo pittoresco, Tomo III, 1843-1844, e as três entregas estão, respectivamente, nos números 19, 20 e 21, todos eles de 1844. Sirva este pequeno exemplo, junto do que dei no início deste ensaio, para recordar as dificuldades com que, em relação aos textos de G arrett, se depara a investigação que procure ser rigorosa, já que a ausência da edição crítica da sua obra nos impede o acesso a textos seguros (e isto é o mais grave) assim como às datas de alguns deles.

A final, também errada está a data do nascimento do escritor, que ali se diz ser 1802 . ( A vontade do escritor? O bservo que na "advertência" de 1821, a O retrato de Vénus, que comecei por reproduzir, o jovem G arrett não fingia ainda ter outra idade, dizendo claramente: "agora, em que conto quase vinte e dois [anos]".) Teófilo B raga, ao reproduzir o texto com o título "Auto-biografia" não corrige a data nem apõe nenhuma nota à mesma, apesar de na sua própria "Introdução" dar como data de nascimento do escritor a correcta de $1799 .{ }^{17}$

Posto isto, reconheçamos a extraordinária importancia desta "B iografia" que, muito antes da biografia levada a cabo pela tarefa ingente de Gomes de Amorim, que só sairá a público cerca de quarenta anos depois, deu a conhecer o percurso biográfico, literário e político do grande escritor, à data em que este devia já ser reconhecido como a maior figura das letras portuguesas do seu tempo.

A par de elementos definitivos para a compreensão e valorização daquele percurso, são-nos proporcionados dados preciosos para a interpretação das obras, de todas e de cada uma, tanto no seu contexto estritamente estético e literário como nos seus contextos políticos e socio-culturais. De facto, a Biografia traça não só a história de um homem mas também, e com ela entrelaçada, a história dos movimentos políticos registados em Portugal desde as invasões napoleónicas até à data da sua escrita. I sto nos faz recordar (e isso nos é também recordado, no fim da Biografia) que por esta mesma altura, G arrett - tal como no fim da "M emória"

17 Vêr Teófilo Braga, obra citada. 
ao Conservatório tinha anunciado - promete "suspender os seus trabalhos de literatura propriamente dita" e ir "dar-se todo a uma tarefa longa, e de ha muito preparada, que ele declara ser hoje o objecto e principal cuidado da sua vida": "a história da revolução de Portugal desde 1820 até ao presente". Ainda ali se diz que para essa "grande empresa" tem já o escritor "ajuntado imensos materiais" e que considera o seu "acabamento e publicação" "quase como um ponto de honra". Sabemos que, afinal, nos anos que ainda Ihe restaram, Garrett, ao contrário do que parece ser o desejo aqui manifestado, por um lado, não suspendeu os trabaIhos literários - que continuaram tanto na elaboração de novos trabalhos como na publicação e organização de obras antigas - e, por outro, não publicou a anunciada "história da revolução de Portugal desde 1820 até ao presente". Neste sentido, pode a Biografia, tanto a parte publicada no Universo pittoresco, como o restante não publicado de que Gomes de Amorim dá conta, ser também considerada como uma parte desse material que dizia ter ajuntado com esse fim.

A encenação da "verdade" (que, ás vezes, pretende ser também, isenção) do que se conta no texto e da credibilidade que procura nos seus leitores (apesar do "anonimato" do seu autor) é feita regularmente ao longo do mesmo, sempre a propósito do biografado ou da sua obra, com frases como: "segundo as suas próprias expressões"; "vivem ainda muitas testemunhas deste facto"; "sabemos, pelo ouvir da própria boca do autor"; "temos-Ihe ouvido protestar que..."; "segundo temos ouvido da própria boca do Sr. G arrett."; "a muitas pessoas de diversos partidos, que assistiram àquela memorável sessão, temos ouvido asseverar que no espaço de duas horas, que durou o discurso [de Porto Pyreu], a câmara toda estava como arrebatada, e sentia dominada toda a sua atenção por um poder sobrenatural."

A passagem que acabo de citar serve-nos igualmente para confirmar como um dos objectivos desta encenação é a de dar credibilidade ao imenso elogio que é feito ao autor. E esta é em minha opinão uma das razões por que a primeira pessoa autoral é disfarçada por uma voz anónima de terceira pessoa.

Ao longo do texto, como já disse, são-nos dadas informações preciosas e directrizes para o entendimento de cada obra en concreto. M as isso vê-lo-emos no comentário que deixo para o final desta análise, sobre a funcionalidade leitora do "prólogo" das Viagens. Por agora, registemos ainda como na Biografia nos é dada conta, sempre em forma de elogio rasgado, do papel decisivo que cada uma das obras de Garrett teve no desenvolvimento de cada um dos variados géneros para cuja introdução, desenvolvimento ou consolidação no panorama da literatura portuguesa contribui de forma decisiva. Podemos, através do que ali se diz, reconstruir a sua concepção de cada um desses géneros.

A oratória, por exemplo, esse "divino dom da eloquência", em que se considerou não ter rival, foi-a Garrett desenvolvendo e consolidando desde a peça em 
que se defendeu no processo sobre o Retrato de Vénus até ao discurso chamado do Porto Pireu, esse "que tem periodos que não envergonhariam a Demóstenes ou a Cicero": o estilo, a voz, o gesto a facilidade e poder da eloquência mediam-se pela "impressão profundíssima" que causavam no auditório ; a viveza das imagens, a facilidade em passar do grave ao sublime, a argumentação lógica e pausada, alternando com o sarcasmo - os elementos com que se construia.

Voltemos, pois, ao "P rólogo" das Viagens. E é aqui que este texto me parece absolutamente fundamental para o conhecimento da experiência de escrita do seu autor, em geral, e para o entendimento, em particular, das Viagens como término e resultado daquela experiência.

Comecemos por recordar como ali se diz que "as Viagens na Minha Terra são um daqueles livros raros que só podiam ser escritos por quem, como o autor [...] de tantas produções de tão variado género, possui todos os estilos" e depois se especifica que esses variados géneros e estilos são: a oratória, a lírica, a epopeia, a tragédia, o drama, a comédia, o tratado administrativo, entre outros. De facto, o livro constitui-se antes de mais como um espaçoso, amplo e entrelaçado espaço multigenérico e para isto nos chama a atenção esta passagem do prólogo, escrita em forma de elogio. Os fios da "embaraçada meada" que ele dirá (no capítulo XXXII) ser este "despropositado e inclassificável livro" são não só “o fio das histórias e das observações" como ali se diz mas também estes tantos e tão variados géneros que o escritor tinha já experimentado, com fortuna, ao longo da sua carreira literária, acrescentado agora pelo novelesco que a narrativa da história "da menina dos rouxinóis", entrecruzada com o teatral, lhe permite praticar. E dificilmente o leitor seguirá cabalmente essa viagem, e literaria e esteticamente a valorizará como há-se ser valorizada, se não tiver em conta esta arquitectura multigenérica em que se desenvolve a sua escrita.

Mas há mais. Também ali se chama a atenção, de novo em forma de elogio, para o vastíssimo conhecimento que o escritor tem das outras literaturas desde a Antiguidade Clássica até aos seus dias, dos seus escritores, das suas tradições, numa longa enumeração. Todos os que temos a experiência do ensino das Viagens sabemos como uma das maiores dificuldades com que se deparam os seus leitores, hoje, reside no desconhecimento, por parte destes leitores, das literaturas, dos géneros, dos escritores e das obras concretas com as quais o livro de G arrett dialoga tantas vezes de forma explícita, outras implicitamente. Também aqui, pois, o "P rólogo" proporciona uma excelente guia para tomar consciência destas dificuldades.

Finalmente, não descura também o "P rólogo"as dimensões ideológicas e éticas do livro. E uma avaliação da obra neste terreno só será consistente se dialogar 
com essas passagens e tiver em conta o que ali nos é dito dos cepticismos e das crenças do seu autor.

Obrigada, pois a G arrett que, em nome "dos editores" e, talvez, para mais livremente fazer o seu elogio, assim nos guiou pelos fios do que poderia parecer uma “embaraçada meada” aumentando o gozo da leitura desse livro extraordinário!

\section{... e conclusões}

Garrett, escreveu Gomes de Amorim, talvez sem pensar no paradoxo para que a sua frase remete: "fingia não querer que se soubesse [que era ele o autor do Arco]". E na Biografia, Garrett, com máscara de outro, informa, a propósito da publicação da Dona Branca como obra póstuma de F.E. que "muitos leitores superficiais a tiveram por obra de Filinto Elíseo". Com a ambiguidade e ambivalência que Ihe conhecemos, comenta: “É contudo visível que foi um inocente disfarce do autor, talvez para lançar poeira nos olhos aos dignos representantes de Fr. Soei ro e de Mestre Gilvaz para que Ihe não perseguissem a D.Branca, como já Ihe tinham perseguido o Retrato de Vénus."

Afinal, só aos olhos de "leitores superficiais" o "inocente disfarce" não é visível; todavia, ainda que "inocente" e "visivel" ele não deixa ("talvez") de querer "lançar poeira" nalguns deles. Fingia não querer que se soubesse? É que fingir não querer não é o mesmo que não querer realmente ...

Depois o gosto pelos fingimentos vinha-lhe de longe se recordamos como já na Lírica de J oão Mínimo Garrett tinha recorrido a eles tanto no "disfarce" do recurso ao manuscrito encontrado como na "noticia do autor" que aprofunda aquele disfarce. Por sinal que, na Biografia, referindo-se a isto diz que se tratou de uma “designação fantástica, que tomou, para prender essa publicação a uma espécie de introdução aventureira e romanesca, que faz lembrar as de - J ededias Cheishbotam - em Sir Walter Scott". Terá sido...mas serviu-Ihe igualmente para fingir que se ocultava ou, de facto, ocultar-se aos ouvidos de leitores superficiais. Ou seria para "Iançar poeira nos olhos" de certa censura? Não esqueçamos que Garrett publica o livro no exílio e que o mesmo contém poemas de exaltação da liberdade...

Para terminar, caberia ainda aqui matizar tudo o que até agora vim dizendo sobre aquele uso de uma "terceira pessoa". Que "terceira pessoa" ou "não-pessoa" é esta? Que outra coisa Ihe poderiamos chamar para dar conta, mais rigorosa, do que realmente, numa perspectiva pragmática, se passa? Que voz é esta, que "primeira pessoa" é esta, apetece-me dizer, que, sem marcas linguísticas de "primeira pessoa", diz: "o Autor", assim Ihe permitindo o fingimento da ocultação? Fiquemos com a pergunta e releiamos, um a um, os sumários das Viagens, esses onde 
Garrett nos diz, de forma "impessoal" "de como o autor"... viajou, escreveu, descobriu, divagou, enfim de como Garrett nos falou do autor-ele próprio.

Lisboa, J aneiro de 1999 